\title{
Avaliação do uso do Self Etching Primer na colagem de braquetes ortodônticos metálicos
}

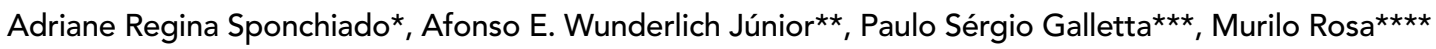

\begin{abstract}
Resumo
Nesta pesquisa laboratorial foi avaliada a resistência de união ao cisalhamento de braquetes metálicos colados ao esmalte dentário bovino, utilizando um sistema adesivo convencional, composto de ácido fosfórico + primer + resina adesiva, e de um sistema SEP (self-etching primer) que combina ácido e primer em uma única solução, avaliado em ambiente seco e úmido (com água). Quarenta e oito incisivos inferiores bovinos foram divididos em três grupos de 16 unidades, que foram assim preparados: grupo 1 (controle) ácido fosfórico 37\% + primer + resina Transbond XT; o grupo 2 Transbond Plus Self Etching Primer em ambiente seco + resina Transbond XT e no grupo 3 o Transbond Plus Self Etching Primer foi aplicado em ambiente úmido com água + Transbond XT. Efetuada a colagem, procedeu-se o ensaio mecânico em uma máquina Instron, a uma velocidade de $1 \mathrm{~mm} / \mathrm{min}$. As médias da resistência de união ao cisalhamento encontradas foram: 9,29MPa para o grupo 1; 10,57MPa para o grupo 2 e $7,45 \mathrm{MPa}$ para o grupo 3 , sendo que os três grupos apresentaram resistência compatível com o uso clínico. Não houve diferença estatisticamente significante entre o sistema convencional e o SEP em ambiente seco, nem em ambiente úmido. Houve redução significativa na resistência de união ao cisalhamento para o SEP em ambiente úmido quando comparado ao SEP em ambiente seco. Concluímos que o Transbond Plus Self Etching Primer apresenta resistência de união ao esmalte similar ao ácido fosfórico $37 \%$ + primer, sendo indicado para uso clínico na colagem de braquetes ortodônticos
\end{abstract}

Palavras-chave: Colagem dentária. Adesivos dentinários. Braquetes ortodônticos. Adesivo autocondicionante.

\section{INTRODUÇÃO}

Os sistemas adesivos convencionais mais utilizados atualmente no processo de colagem de braquetes ortodônticos ao esmalte apresentam três agentes: um condicionador ácido de esmalte, um primer e uma resina adesiva. Um sistema de colagem recentemente lançado apresenta como característica combinar o agente condicionador e o primer em uma única solução, denominada self-etching primer (SEP). Este produto dispensa

* Especialista em Radiologia Odontológica pela EAP/ABO-SC e Especialista em Ortodontia e Ortopedia Facial pela EAP/ABO-SC.

** Especialista em Ortodontia e Ortopedia Facial pela EAP/ABO-SC. Professor do curso de Aperfeiçoamento em Ortodontia da EAP/ABO-SC

*** Mestre em Ortodontia pela UFRJ. Professor do curso de Especialização em Ortodontia da EAP/ABOSC.

**** Mestre em Ortodontia pela UFRJ. Coordenador do curso de Especialização em Ortodontia da EAP/ABOSC. 
a necessidade de enxágüe e de fotopolimerização, tornando o processo de colagem mais rápido, mais simples e fácil, reduzindo o custo para o profissional e, indiretamente, para o paciente ${ }^{26}$.

Este self-etching primer foi utilizado inicialmente em dentina ${ }^{11}$, e demonstrou bom potencial de união à estrutura dental. Bishara et al. ${ }^{7}$ testaram o uso de um SEP na colagem de braquetes ortodônticos e obtiveram resultados variados, dependendo do adesivo utilizado, mas afirmaram que este produto pode ser promissor na colagem de braquetes. Cinader ${ }^{12}$ observou bons resultados do SEP na colagem de braquetes ortodônticos em ambiente seco e úmido. Bishara, Vonwald e Laffoon ${ }^{4}$ compararam um SEP com um sistema adesivo convencional na colagem de braquetes, e observaram que o SEP resultou numa redução significativa da resistência de união ao cisalhamento, porém clinicamente aceitável. Bishara et al. ${ }^{7}$ avaliaram a resistência de união ao cisalhamento de três SEPs e encontraram valores considerados clinicamente aceitáveis para os três, sendo que a resistência encontrada com um deles foi similar à do ácido fosfórico. Esses autores sugeriram que mais pesquisas deveriam ser realizadas para determinar a resistência de união ao cisalhamento na colagem de braquetes ortodônticos com os novos SEPs nos primeiros 30min após a colagem, simulando o tempo clínico em que os arcos são amarrados.

Com o objetivo de contribuir com estas pesquisas, uma vez que resultados positivos com o self-etching primer são de grande interesse na clínica ortodôntica, este trabalho teve por objetivo avaliar, in vitro, a resistência de união ao cisalhamento de braquetes metálicos utilizando um sistema adesivo que combina ácido e primer em uma única solução (o Transbond Plus Self Etching Primer), em ambiente seco e úmido, nos primeiros 20 min após a colagem, comparando-os a um sistema de colagem convencional (ácido fosfórico $37 \%+$ primer + Transbond XT).

\section{MATERIAL E MÉTODOS}

Foram utilizados 48 dentes bovinos, incisivos inferiores permanentes, recentemente extraídos, divididos em três grupos de 16 dentes cada. O critério para seleção dos dentes incluiu: o esmalte dental intacto, sem trincas e ausência de prévia aplicação a agentes químicos (timol, peróxido de hidrogênio, álcool ou formol). Os corpos de prova foram preparados da seguinte maneira: após as extrações dos dentes e remoção dos tecidos periodontais, estes foram lavados e armazenados em soro fisiológico a $4^{\circ} \mathrm{C}$. Posteriormente, a porção radicular e a polpa dos dentes foram removidas, permitindo a adaptação das coroas em cilindros de PVC de $25 \mathrm{~mm} \times 20 \mathrm{~mm}$. As coroas foram incluídas nestes cilindros contendo resina acrílica, de tal modo que a porção mais proeminente e central da face vestibular dos dentes ficasse exposta perpendicularmente ao cilindro. Para se obter uma superfície dentária lisa, plana e paralela à base do cilindro, desgastou-se a porção vestibular dos dentes que permaneceu acima do cilindro em uma politriz Panambra (modelo DP-10) com lixas 220, 400 e 600, com resfriamento de água. Os corpos de prova foram aleatoriamente divididos em três grupos e numerados. Foi realizada profilaxia dos dentes com taça de borracha e pedra pomes (com granulação fina e sem flúor) durante 10s e após, enxágüe com spray de ar-água por igual tempo.

Foram utilizados braquetes metálicos para incisivos centrais superiores, da técnica Standard Edgewise, com canaleta 0,022" x 0,028" DynaLock da 3M - Unitek, providos de retenção mecânica na base, do tipo sulco. A área da base dos braquetes fornecida pelo fabricante é de $14,62 \mathrm{~mm}^{2}$.

Foram utilizados dois sistemas adesivos fotopolimerizáveis para colagem direta de braquetes ortodônticos, de acordo com as instruções do fabricante:

a) $O$ sistema adesivo utilizado no grupo 1 (controle) foi um sistema convencional, com três componentes: um agente condicionador ácido, um primer e uma resina adesiva:

- agente condicionador utilizado foi o ácido 
fosfórico $37 \%$ com a denominação comercial Transbond XT Etching Gel System da 3M Unitek, Monrovia - CA, EUA.

- primer Transbond XT Light Cure Adhesive Primer da 3M Unitek;

- resina composta Transbond XT Light Cure Adesive Paste da 3M Unitek.

b) O sistema adesivo utilizado nos grupos $2 \mathrm{e}$ 3 foi um sistema que combina o ácido e o primer em uma única solução, denominado self etching primer (SEP):

- foi utilizado o Transbond Plus Self Etching Primer da 3M Unitek, Monrovia - CA, EUA (Fig.1);

- a resina composta utilizada para a colagem dos braquetes foi o Transbond XT Light Cure Adesive Paste da 3M Unitek, Monrovia - CA, EUA, a mesma utilizada no grupo controle.

Os braquetes foram colados de acordo com três protocolos:

a) Grupo 1 (controle) - 16 dentes foram secos com spray de ar por 10s, condicionados com ácido fosfórico $37 \%$ por 15 s, lavados por 20 s e secos por 10s. O primer foi aplicado com um pincel microbrush na área da base do braquete; a resina composta aplicada em toda a base do braquete e este posicionado sobre o dente, com o slot paralelo e a uma distância de $7 \mathrm{~mm}$ do bordo incisal;

b) Grupo 2 - 16 dentes foram secos com spray de ar por 10s. Em seguida foi realizada a aplicação do SEP de acordo com as instruções do fabricante, ou seja, após a mistura dos componentes, friccionou-se o líquido sobre a superfície do esmalte por 3s. Retornou-se a ponta aplicadora ao tubo para recarregá-la com material e repetiu-se o procedimento nos demais dentes. Com os dentes preparados, aplicou-se um leve jato de ar livre de óleo por $3 \mathrm{~s}$ em cada dente, ficando estes prontos para a colagem dos braquetes. A resina composta foi aplicada em toda base do braquete, e este posicionado sobre o dente, como no grupo 1;

c) Grupo 3 - em 16 dentes o excesso de água foi removido com uma bolinha de algodão. Foi então aplicado o SEP sobre a superfície do esmalte úmido por 3s e evaporado com suave spray de ar. A resina foi aplicada sobre toda a base do braquete e este posicionado sobre o dente, como nos outros grupos.

Cada braquete foi comprimido com uma agulha de Gillmore posicionada no centro do braquete, com 451,6g de força por 10s, com o objetivo de reduzir e padronizar a espessura do adesivo. Foi removido o excesso de material com uma sonda exploradora $n^{\circ} 5$. Após a remoção da agulha de Gillmore, a resina foi fotopolimerizada por 20s (10s na mesial e 10s na distal, conforme recomendações do fabricante), com uma unidade fotopolimerizadora de luz visível 2500,

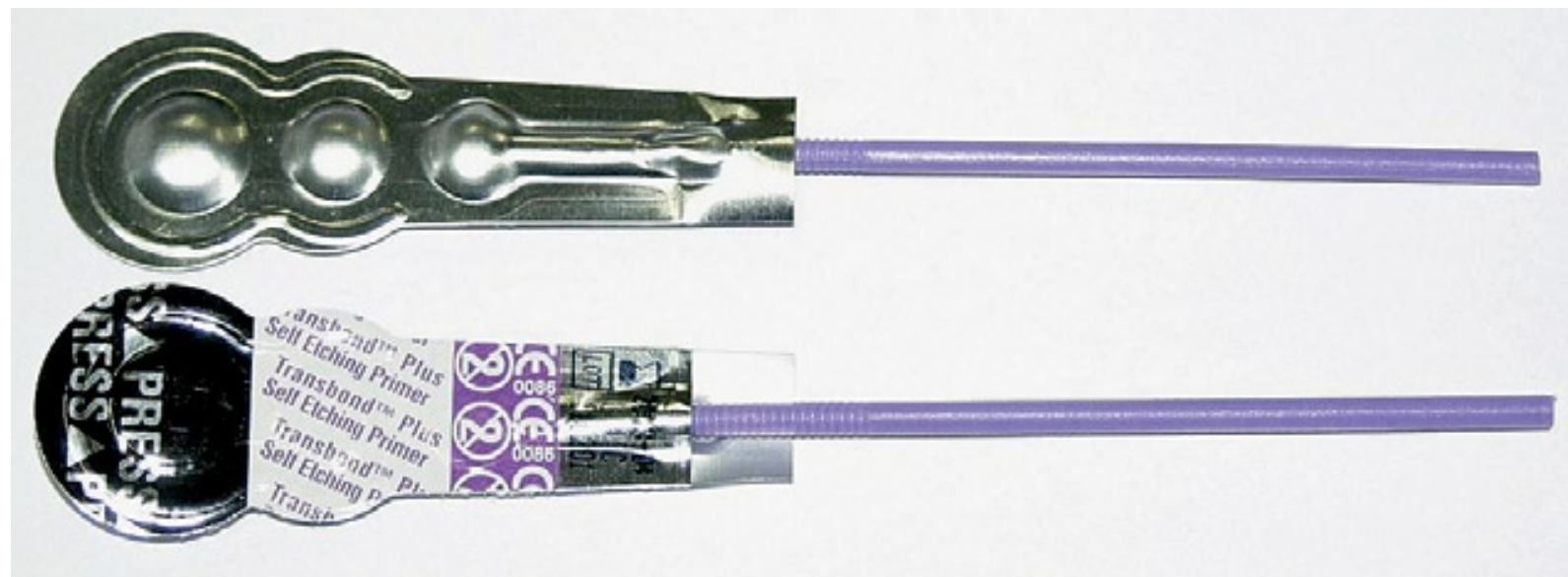

FIGURA 1 - Transbond Plus Self Etching Primer (vista superior e inferior). 
3M (3M, USA - modelo 5560AF), com intensidade de $480 \mathrm{~mW} / \mathrm{cm}^{2}$, aferida por um radiômetro Demetron (modelo 100). O fotopolimerizador foi acoplado a um regulador de voltagem (estabilizador) SMS - Revolution II, para evitar variações na voltagem elétrica.

Os corpos de prova foram montados no dispositivo de fixação de uma máquina de ensaios mecânicos Instron (Instron Universal 4440-C6600, USA) para os testes de resistência ao cisalhamento, de tal modo que as bases das aletas dos braquetes ficassem perpendiculares à força aplicada (FIG. 2A, B), a uma velocidade de $1,0 \mathrm{~mm} / \mathrm{min}$., sendo o peso da célula de carga aplicada de 2000 Newtons.

A carga, no momento da descolagem de cada braquete, foi registrada na Instron em quiloNewton, que posteriormente foi convertida para Newton e transformada em tensão, expressos em MPa.

\section{Análise estatística}

Após os testes de resistência de união ao cisa-

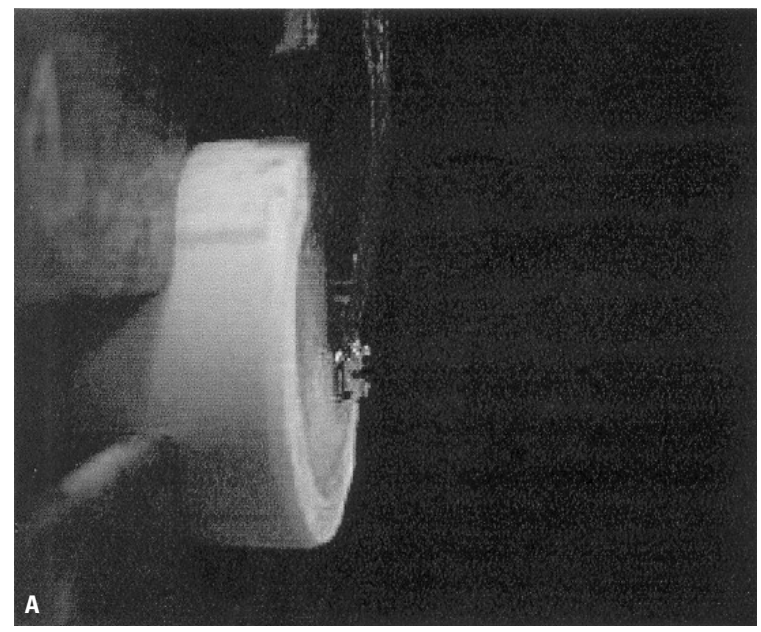

lhamento, foi aplicado o tratamento estatístico por meio da análise de variância (ANOVA) de um e mais fatores, com nível de significância de $5 \%(\mathrm{p}<0,05)$ para analisar se haviam diferenças estatisticamente significativas entre os três grupos. Havendo diferenças entre os grupos, realizou-se o teste LSD com nível de significância de $5 \%(\mathrm{p}<0,05)$ para se diferenciar estatisticamente os grupos referentes.

\section{RESULTADOS}

Determinou-se a resistência de união ao cisalhamento em MPa dividindo-se a carga em Newtons pela área da base dos braquetes $\left(14,62 \mathrm{~mm}^{2}\right)$.

A média da resistência de união ao cisalhamento para o grupo tratado com ácido fosfórico + primer (grupo 1) foi de 9,29MPa; para o SEP em ambiente seco (grupo 2) de 10,57MPa e para o SEP em ambiente úmido de 7,45MPa (Tab. 1). A média da resistência de união ao cisalhamento do grupo 1 (controle) foi bastante próxima da média obtida no grupo 2. No grupo 2 obteve-se a

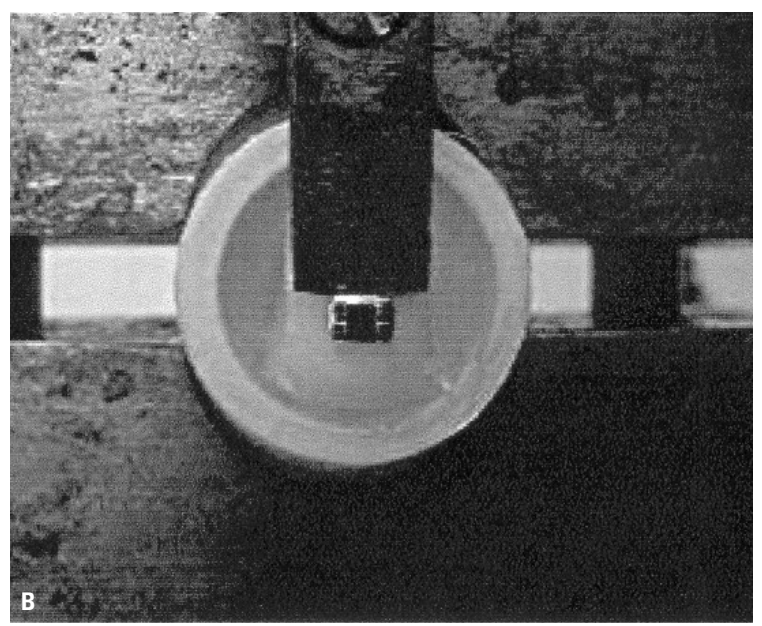

FIGURA 2 A, B) Aplicação da carga de cisalhamento.

\begin{tabular}{|c|c|c|c|c|}
\hline \multicolumn{5}{|c|}{ Tensão MPa } \\
\hline & Média & $\mathbf{N}$ & Desvio Padrão & Mediana \\
\hline Ac. Fosfórico & 9,29 & 16 & 3,6197 & 8,78 \\
\hline SEP seco & 10,57 & 16 & 3,1851 & 11,14 \\
\hline SEP úmido & 7,45 & 16 & 3,6384 & 6,55 \\
\hline Todos os grupos & 9,11 & 48 & 3,6504 & 8,83 \\
\hline
\end{tabular}


melhor resistência de união ao cisalhamento.

O grupo 3 (SEP úmido) apresentou diferença estatisticamente significante em relação ao grupo 2 (SEP seco). Não apresentaram diferenças estatisticamente significantes entre os grupos 1 (ácido fosfórico 37\% + primer) e 2 (SEP seco), nem o 1 (ácido fosfórico 37\% + primer) e 3 (SEP úmido).

\section{DISCUSSÃO}

Para a colagem de braquetes ortodônticos, o condicionador de esmalte mais utilizado ainda é o ácido fosfórico a 37\%. Os sistemas adesivos convencionais são compostos por três agentes: um ácido (geralmente o fosfórico 37\%), um primer e uma resina adesiva. Uma inovação é um produto que combina o agente condicionador e o primer em uma única solução, sem necessidade de enxágüe, denominada self-etching primer (SEP) ou primer autocondicionador. O SEP foi inicialmente testado para uso em dentina, e os resultados mostraram efeito significativo na adesão, conforme Chigira et al. ${ }^{11}$. A parte ácida do SEP dissolve a lama dentinária e a incorpora na mistura. A solução ácido/primer também desmineraliza a dentina e envolve as fibras colágenas e cristais de hidroxiapatita. Este simultâneo condicionamento/primer possibilita que o monômero penetre na dentina, produzindo uma camada híbrida, conforme Nishida et al. ${ }^{24}$; Nakabayashi (1991, apud BISHARA et al. $\left.{ }^{7}, 2002\right)$. Nishida et al. ${ }^{24}$ testaram um sistema SEP (KB100) em esmalte e dentina e não encontraram diferença significativa na resistência de união ao esmalte, enquanto que em dentina, o novo sistema demonstrou aumento significativo na resistência de união. Perdigão et al. ${ }^{27}$ avaliaram um sistema SEP (Clearfil Linear Bond 2) e observaram que o padrão de condicionamento obtido com o SEP foi pouco definido e mais superficial quando comparado ao padrão obtido com ácido fosfórico a $10 \%$ e $37 \%$, ácido maleico a $10 \%$ e ácido nítrico a 2,5\%, mas não afetou a média da resistência de união ao cisalhamento ao esmalte. Ferrari et al. ${ }^{14}$ investigaram a capacidade de selamento da
Clearfil Linear Bond 2 em restaurações de classe V e obtiveram bons resultados tanto clínica quanto laboratorialmente quando o SEP foi aplicado por 60 s (o dobro do tempo recomendado pelo fabricante). Bishara et al. $^{7}$ avaliaram a resistência de união ao cisalhamento de braquetes ortodônticos colados com um sistema SEP e obtiveram resultados variados, dependendo do adesivo utilizado. Novamente Bishara et al. ${ }^{3}$ compararam um sistema SEP a outros condicionadores e não obtiveram bons resultados com o uso do SEP, sugerindo que mais pesquisas fossem feitas para encontrar uma combinação de ácido/primer adequada. Lopes, Perdigão e Ambrose ${ }^{20}$ concluíram que um sistema SEP (LP1) interage com a dentina de maneira análoga a um sistema adesivo convencional. Breschi et al. ${ }^{8}$ verificaram que um sistema SEP apresentou o padrão de desmineralização de esmalte similar ao padrão obtido pelo ácido fosfórico a 35\% e resistência de união também similar aos adesivos convencionais. Rosa e Perdigão ${ }^{32}$ avaliaram a resistência de união ao esmalte de um sistema SEP (Prompt L-Pop) e encontraram bons resultados. Bishara et al. ${ }^{5}$ compararam o SEP Prompt L-Pop a um sistema adesivo convencional e afirmaram que o uso do SEP para colagem de braquetes ortodônticos resultou numa redução significativa, porém clinicamente aceitável da força de resistência ao cisalhamento. Para Leinfelder ${ }^{19}$ o maior avanço no desenvolvimento de sistemas sem condicionamento em associação com agentes de colagem foi o Prompt L-Pop, identificado por alguns autores como a Sexta Geração de adesivos, que apresenta vantagens como não necessitar de condicionamento ácido, nem enxágüe, nem secagem, nem fotopolimerização; apenas a simples aplicação e dispersão com ar são necessários.

Em outubro de 2001 a 3M Unitek lançou no mercado um produto idêntico ao Prompt L-Pop, desenvolvido especificamente para ortodontis$\operatorname{tas}^{23}$, o Transbond Plus Self-Etching Primer, produto utilizado neste trabalho. O Transbond SEP contém ésteres fosfóricos como condicionador 
de esmalte e não ácido fosfórico como os condicionadores convencionais. Os seus componentes não podem ser expressos em porcentagens, já que trata-se de uma molécula bifuncional que contém as duas partes: condicionador e primer. Adicionalmente, o produto contém resinas de metacrilato, conforoquinona como "fotoiniciador", água destilada como solvente e outros componentes menores (KHACHATOORIAN apud RODRIGUEZ et al. ${ }^{31}$, 2002). Segundo Miller ${ }^{23}$, a química do Transbond SEP é similar à do ácido fosfórico, com duas cadeias de primer que formam uma matriz sólida de primer após polimerizar. O líquido começa a condicionar o esmalte assim que é aplicado, mas se transforma em primer assim que as duas cadeias hidroxílicas são convertidas e o hidrogênio é liberado. Como não permanece ácido no esmalte, não há necessidade de enxágüe. Como o monômero que causa a desmineralização é também responsável pela adesão, a profundidade da zona de desmineralização corresponde à profundidade da penetração do monômero polimerizado, resultando em uma completa zona híbrida.

Segundo Cinader ${ }^{12}$ o padrão de condicionamento do esmalte obtido com o Transbond SEP é similar aquele obtido com o ácido fosfórico a 37\%. O grupo fosfato do éster ácido fosfórico metacrilato (ingrediente ativo) dissolve o cálcio e o remove da hidroxiapatita. Todavia, antes de ser removido, o cálcio forma um complexo com o grupo fosfato e é incorporado em uma rede quando o primer polimeriza. Desta maneira, o ácido é neutralizado. $\mathrm{O}$ condicionamento e a penetração nos prismas de esmalte são simultâneos e, desta maneira, a profundidade do condicionamento e a penetração do primer são idênticas. Cinader ${ }^{12}$ afirma que o desempenho do Transbond SEP é tão bom quanto os sistemas convencionais, com a vantagem de economizar tempo. A 3M-Unitek (fabricante) afirma que o Transbond SEP tolera pequena quantidade de umidade, pois contém componentes hidrofílicos; e que o produto contém e libera flúor. Arnold,Combe e Warford ${ }^{2}$ avaliaram o Transbond
SEP e afirmaram que este cumpre os requisitos para a colagem clínica de braquetes com eficiência. Rodriquez et al. ${ }^{31}$ testaram os Transbond SEP a afirmaram que este pode ser utilizado com confiança, tendo como vantagens a simplificação do processo de colagem, diminuição significativa do tempo clínico (de 23s a 29s por dente, gastos com o sistema convencional, para $5 \mathrm{~s}$ a 6 s com o SEP) com maior comodidade tanto para o profissional quanto para o paciente. Baseados no que foi exposto acima, utilizamos o Transbond Plus SelfEtching Primer em nossa pesquisa.

Nesta pesquisa, obtivemos como média da resistência de união ao cisalhamento para o grupo tratado com ácido fosfórico + primer (grupo 1) de 9,29MPa; para o SEP em ambiente seco (grupo 2) de $10,57 \mathrm{MPa}$ e para o SEP em ambiente úmido de 7,45MPa (Tab. 4). A média da resistência de união ao cisalhamento do grupo 1 (controle) foi bastante próxima da média obtida no grupo 2 , sendo que neste obteve-se a melhor resistência de união ao cisalhamento.

Verificamos que o grupo 3 (SEP úmido) apresentou diferença estatisticamente significante em relação ao grupo 2 (SEP seco). Não verificamos diferenças estatisticamente significantes entre os grupos 1 (ácido fosfórico 37\% + primer) e 2 (SEP seco), nem o 1 (ácido fosfórico $37 \%+$ primer) e 3 (SEP úmido). Os resultados desta pesquisa corroboram os achados de Cinader ${ }^{12}$, onde o Transbond SEP apresentou desempenho tão bom quanto os sistemas convencionais. A afirmação do fabricante (3M - Unitek), de não existir diferença na resistência de união ao cisalhamento quando o SEP é usado em ambiente seco ou úmido não foi confirmada neste estudo.

Comparados com os resultados obtidos em outros estudos que também utilizaram o ácido fosfórico 37\% + Primer + Transbond XT, verificamos que os valores obtidos em nossa pesquisa $(9,29 \mathrm{MPa})$ estão de acordo com os valores obtidos por Arnold, Combe e Warford ${ }^{2}$, que foi de 9,7MPa; com Bishara et al. $^{5}$ que obtiveram 10,4MPa; 
Bishara et al. ${ }^{3}$ também obtiveram 10,4MPa. Correr Sobrinho ${ }^{13}$ obteve valores pouco menores, de 7,33MPa, assim como Wunderlich Júnior ${ }^{36}$ que obteve $5,87 \mathrm{MPa}$ e Aasrum et al. ${ }^{1}$, que obtiveram $5,1 \mathrm{MPa}$. Gazola ${ }^{15}$ obteve valores de $5,23 \mathrm{MPa}$, $12,37 \mathrm{MPa}$ e $5,87 \mathrm{MPa}$ variando de acordo com o tipo de braquete utilizado. Enquanto Rix, Foley e Mamandras ${ }^{30}$ encontraram valores bem maiores, de 20,19MPa e Hobson, Ledvinka e Meechan ${ }^{17}$ obtiveram 15,69MPa. Esta variabilidade deve-se à falta de padronização dos testes, já citada por Gazola $^{15}$ e Richard e Chevitarese ${ }^{29}$.

Devido à escassez de pesquisas desenvolvidas até o momento com o Transbond Plus SelfEtching Primer, tivemos pouca possibilidade de comparar os resultados obtidos. Arnold et al. ${ }^{2}$ utilizaram o Transbond SEP em ambiente seco e obtiveram médias de 8,0MPa quando a colagem foi realizada 15 s após a aplicação do SEP; $8,4 \mathrm{MPa}$ quando a colagem foi realizada $2 \mathrm{~min}$ após a aplicação do SEP e 9,8MPa quando a colagem foi realizada $10 \mathrm{~min}$ após a colagem, valores pouco menores, porém de acordo com os valores obtidos em nossa pesquisa. Rodriguez et al. ${ }^{31}$ também utilizaram o Transbond SEP, realizando testes de resistência à tração, obtendo médias de $6,25 \mathrm{MPa}$, mas segundo Yamada ${ }^{37}$ os resultados de testes de tração e cisalhamento não podem ser comparados. Comparando os resultados obtidos em pesquisas desenvolvidas com o SEP Prompt L-Pop (quimicamente idêntico ao Transbond SEP, segundo a 3M-Unitek) observamos que Bishara, Vonwald e Laffoon ${ }^{4}$ e Bishara et al. ${ }^{7}$ obtiveram resistência de união ao cisalhamento média de $7,1 \mathrm{MPa}$, semelhante à média obtida em nosso estudo com o SEP em ambiente úmido (7,45MPa). Nestes dois últimos estudos os autores sugerem que estudos sejam realizados com os SEPs nos primeiros 30 min após a colagem, simulando o tempo clínico em que os arcos são amarrados (uma vez que eles testaram $48 \mathrm{~h}$ após a colagem). Em nosso estudo, os braquetes foram submetidos à carga num intervalo de tempo compreendido entre $10 \mathrm{~min}$ e $20 \mathrm{~min}$, e os resultados não fica- ram abaixo dos obtidos por Bishara, Vonwald e Laffoon $^{4}$ e Bishara et al. ${ }^{7}$, sugerindo que o tempo de aplicação da carga não influencia na resistência de união ao cisalhamento; no entanto, mais pesquisas são necessárias para que se possa fazer esta afirmação.

Como os resultados médios obtidos para a resistência de união ao cisalhamento nos três grupos são superiores ao preconizado por Reynolds ${ }^{28}$ de 4,9MPa, podemos afirmar que é possível obter sucesso na colagem clínica tanto com ácido fosfórico $37 \%$ + primer, quanto com o SEP em ambiente seco ou úmido. Este resultado comprovou a praticidade, facilidade e rapidez no uso do SEP, confirmando a economia de tempo descrita por Rodriguez et al. ${ }^{31}$; Leinfelder ${ }^{19}$; Bishara et al. ${ }^{7}$, corroborando com Miller ${ }^{23}$, quando diz que o SEP revolucionou o processo de colagem e que os sistemas adesivos convencionais estarão ultrapassados dentro de poucos anos.

\section{CONCLUSÕES}

A partir dos resultados obtidos nesta pesquisa, foi possivel concluir que:

a) a média da resistência de união ao cisalhamento na colagem de braquetes utilizando um sistema adesivo convencional composto por ácido fosfórico $37 \%$ + primer foi de 9,29MPa (grupo 1);

b) a média da resistência de união ao cisalhamento na colagem de braquetes utilizando um sistema SEP em ambiente seco foi de 10,57MPa (grupo 2). A média da resistência de união ao cisalhamento na colagem de braquetes utilizando um sistema SEP em ambiente úmido (com água) foi de 7,45MPa (grupo 3);

c) não houve diferença estatisticamente significante entre o grupo 1 e o grupo 2, portanto o Transbond Plus Self Etching Primer apresenta resistência similar ao sistema convencional (ácido fosfórico $37 \%$ + primer), podendo ser utilizado com segurança na clínica ortodôntica. Não houve diferença estatisticamente significante entre o grupo 1 e o grupo 3, portanto o Transbond Plus Self 
Etching Primer pode ser utilizado em ambiente úmido. Houve uma diminuição estatisticamente significativa na resistência de união ao cisalhamen- to do grupo 2 para o 3 , indicando que a umidade afeta de forma negativa a colagem, quando utilizamos o Transbond SEP.

\title{
Assessment of the Self-Etching Primer on bonding of metallic orthodontic brackets
}

\begin{abstract}
This research evaluated the shear bond strength of metallic brackets bonded to bovine teeth, using conventional adhesive system consisting of phosphoric acid + primer + adhesive resin, and a system SEP (self-etchingprimer) that combines acid and primer in one solution. The SEP system was evaluated in either dry and moist (water) environments. Forty-eight lower bovine incisors teeth were divided in three groups of sixteen units each one, prepared as following: group 1(control) phosphoric acid 37\% + primer + Transbond XT resin; group 2 Transbond Plus Self Etching Primer in dry environment + Transbond XT resin, and group 3 the Transbond Plus Self Etching Primer applied in moist environment + Transbond XT. After bonding, the mechanical test was performed with an Instron machine (crosshead speed of $1 \mathrm{~mm} / \mathrm{min}$ ). The shear bond strength were: 9,29 $\mathrm{MPa}$ for group 1; 10,57 MPa for group 2 and 7,45 MPa for group 3. All groups showed clinical acceptable resistance. There wasn't significant difference between conventional system and the SEP in dry environment, neither in moist environment. However, there was a significant reduction in the shear bond strength for the SEP in moist environment when compared with SEP in dry environment. It was concluded that Transbond + Self Etching Primer showed shear bond strength to enamel similar to phosphoric acid 37\% + primer, therefore it is indicated to clinically bond orthodontic brackets.
\end{abstract}

Key words: Enamel bond. Dentin adhesive. Orthodontic brackets. Self-etching primer.

\section{REFERÊNCIAS}

1. AASRUM, E. et al. Tensile bond strength of orthodontic brackets bonded with a fluoride-releasing light-curing adhesive. An in vitro comparative study. Am J Orthod Dentofacial Orthop, St. Louis, v.104, no.1, p. 48-50, July 1993.

2. ARNOLD, R. W.; COMBE, E. C.; WARFORD JR., J. H. Bonding Os stainless steel brackets to enamel with a new self-etching primer. Am J Orthod Dentofacial Orthop, St. Louis, v.122, no.3, p. 274-276, Sept. 2002.

3. BISHARA, S. E. et al. Comparisons of two approaches for removing excess adhesive during the bonding procedure. Angle Orthod, Appleton, v. 70, no. 2, p. 149-153, Apr. 2000.

4. BISHARA, S. E.; VONWALD, L.; LAFFOON, J. F.Effect of a selfetch primer/adhesive en the shear bond strength of orthodontic brackets. Am J Orthod Dentofacial Orthop, St. Louis, v.119, no. 6, p. 621-624, June 2001.

5. BISHARA, S. E.; LAFFOON, J. F.; VONWALD, L. Evaluation of nonrinse conditioning solution and a compomer as na alternative method of bonding orthodontic bracket. Angle Orthod,
Appleton, v.71, no. 6, p. 461-465, 2001.

6. BISHARA, S. E.; LAFFOON, J. F.; VONWALD, L. Effect of time on the shear bond strength of cyanocrylate and composite orthodontic adhesives. Am J Orthod Dentofacial Orthop, St. Louis, v. 121, no. 3, p. 297-300, Mar. 2002.

7. BISHARA, S. E. et al. Effect of a fluoride-releasing self-etch acidic primer on the shear bond strength of orthodontic brackets. Angle Orthod, Appleton, v. 72, no. 3, p.199-202, 2002.

8. BRESCHI, L. et al. Ultramorphology and shear bond strengths of self-etching adhesives on enamel. J Dent Res, Chicago, v. 78, p. 475, 1999. Abstract 2957.

9. BUONOCORE, M. G. Principles of adhesive retention and adhesive restorative material. J Am Dent Assoc, Chicago, v. 67, no. 3, p. 382-391, Sept. 1963.

10. ÇEHERELI, Z.; ALTAY, N. Effects of nonrinse conditioner and $17 \%$ ethylenediaminetetraacetic acid on the etch pattern of intact permanent enamel. Angle Orthod, Appleton, v. 70, no.1, p. 22-27, Feb. 2000. 
11. CHIGIRA, $\mathrm{H}$. et al. Effect of the self etching dentin primers on the bonding efficacy of a dentin adhesive. Dent Mater J, Tokyo, v. 8 , no. 1 , p. $86-92,1989$

12. CINADER, D. Chemical processes and performance comparisons of Transbons Plus Self Etching Primer. (Senior product development engineer, 3M). Sept. 1999. Disponível em: <http://www.3m.com/unitek>. Acesso em: 21 ago. 2002

13. CORRER SOBRINHO, L. et al. Avaliação da resistência ao cisalhamento na colagem de braquetes, utilizando diferentes materiais. Rev ABO Nac, Rio de Janeiro, v. 9, n. 2, p.157-162, jun./jul. 2001.

14. FERRARI, M. et al. Effect of two etching times on the sealing ability of Clearfil Liner Bond 2 in class $V$ restorations. Am J Dent, San Antonio, v.10, no. 2, p. 66-70, Apr. 1997.

15. GAZOLA, S. Avaliação da resistência de união sob cisalhamento de braquetes de porcelana com e sem retenção mecânica. 2001. 106 f. Trabalho de Conclusão de Curso (Especialização em Ortodontia e Ortopedia Facial)-Escola de Aperfeiçoamento Profissional, ABOSC, Florianópolis, 2001

16. GRANDHI, R. K.; COMBE, E. C.; SPEIDEL, T. M. Shear bond strength of steinless steel orthodontic brackets with a moistureinsensitive primer. Am J Orthod Dentofacial Orthop, St. Louis, v.119, no. 3, p. 251-255, Mar. 2001.

17. HOBSON, R. S.; LEDVINKA, J.; MEECHAN, J. G. The effect of moisture end blood contamination of bond strength of a new orthodontic bonding material. Am J Orthod Dentofacial Orthop, St. Louis, v.120, no.1, p. 54-57, July 2001.

18. HOGERVORST, W. L. VAN W.; FELIZER, A. J. ; PRAHL-ANDERSEN, B. The Air-abrasion technique versus the conventional acid-etching technique: a quantification of surface enamel loss and a comparison of shear bond strength. Am J Orthod Dentofacial Orthop, St. Louis, v.117, no.1, p. 20-26, Jan. 2000

19. LEINFELDER, K. F. Dentin adhesives for the twenty-first century. Dent Clin North Am, Philadelphia, v. 45, no.1, p.1-6, Jan. 2001.

20. LOPES, M.; PERDIGÃO, J.; AMBROSE, W. W. Ultramorphological study of dentin treated with a simplified adhesive. J Dent Res, Chicago, v. 78, p. 475, 1999. Abstract 2955

21. LOPES, G. C. et al. Dental adhesion: present state of the art and future perspective. Quintessence Int, Berlin, v. 33, no. 3, p. 213-224, 2002

22. MILIA, E. et al. In vivo hybridization of two self-etching adhesive system. J Dent Res, Chicago, v. 78, p. 475, 1999. Abstract, $2960 \mathrm{~b}$

23. MILLER, R. A. Laboratory and clinical evaluation of a self-etching primer. J Clin Orthod, Boulder, v. 35, no.1, p. 42-45, Jan. 2001

24. NISHIDA, K. et al. Development of a new bonding system. J Dent Res, Chicago, v. 72, p.137, 1993. Abstract, 267.
25. OESTERLE, L. J.: SHELLHART, W. C.: BELANGER, G. K. The use of bovine enamel in bonding studies. Am J Orthod Dentofacial Orthop, St. Louis, v. 114, no. 5, p. 514-519, Nov. 1998.

26. PASCOTTO, R. C.; HOEPPNER, M. G.; PEREIRA, S. K. Materiais de colagem e cimentação em ortodontia : parte II: sistemas adesivos resinosos. R Dental Press Ortodon Ortop Facial, Maringá, v. 7, n. 3, p.121-128, maio/jun. 2002.

27. PERDIGÃO, J. et al. Effects of a self-etching primer on enamel shear bond strengths and SEM morphology. Am J Dent, San Antonio, v.10, no. 3, p.141-146, June 1997.

28. REYNOLDS, J. R. A Review of direct orthodontic bonding. $\mathbf{B r} \mathbf{J}$ Orthod, London, v. 2, no. 3, p.171-178, July 1975.

29. RICHARD, G. M.; CHEVITARESE, O. Condicionamento ácido do esmalte dentário: efeito do tempo sobre a resistência ao cisalhamento e modos de fratura da colagem. Rev SBO, Rio de Janeiro, v. 3, n. 1, p. 21-24, jan./jun. 1996.

30. RIX, D.; FOLEY, T. F.; MAMANDRAS, A. Comparison of bond strength of three adhesives: composite resin, hybrid GIC, and glass-filled GIC. Am J Orthod Dentofacial Orthop, St. Louis, v.119, no.1, p. 36-42, Jan. 2001.

31. RODRIGUEZ, G. C. D. et al. Avaliação "in vitro" da resistência à tração de braquetes metálicos colados com o novo sistema adesivo "self etching primer" (SEP). Ortodontia, São Paulo, v. 35, n.2, p. 28-34, abr./jun. 2002.

32. ROSA, B. T.; PERDIGÃO, J. Bond strengths of nonrinsing adhesives. Quintessence Int, Berlin, v. 31, no.5, p.353-358, 2000.

33. SANTOS, P. C. F. et al. Colagem em ambiente úmido: avaliação da capacidade de resistência à tração de braquetes metálicos. R Dental Press Ortodon Ortop Facial, Maringá, v. 5, n. 6, p. 33-43, nov./dez. 2000

34. SPONCHIADO, A. R. Avaliação do Self etching primer na colagem de braquetes ortodônticos metálicos. 2002. 94f. Trabalho de Conclusão de Curso (Especialização em Ortodontia e Ortopedia Facial) - Curso de Especialização em Ortodontia, Escola de Aperfeiçoamento Profissional, ABOSC, Florianópolis, 2002

35. 3M Unitek Orthodontic Products. Transbond plus self etching primer: bonding reference guide. Disponível em: <http:// www.3Munitek.com>. Acesso em: 21 ago. 2002

36. WUNDERLICH JUNIOR, A. E. Avaliação laboratorial da resistência de união de braquetes ortodônticos colados ao esmalte. 2001. 116 f. Monografia (Especialização em Ortodontia e Ortopedia Facial)-Curso de Especialização em Ortodontia Escola de Aperfeiçoamento Profissional, ABOSC, Florianópolis 2001

37. YAMADA, T.; SMITH, D. C.; MAYJOR, R. Tensile and shear bond strength of orthodontic direct bonding adhesive. Dent Mater Copenhagen, v. 4, p. 243-250, Oct. 1988.
Endereço para correspondência

Adriane Regina Sponchiado

E-mail: adri@viawave.com.br 